\title{
Autism-A Multifaceted Diffuse Pathology
}

\author{
Radek Ptacek ${ }^{1,2 *}$, Dagmar Brejlova1, Hana Ptackova ${ }^{1}$, Lucie Domkarova ${ }^{1}$, Jiri Raboch ${ }^{1}$ and George B Stefano ${ }^{1,2}$
}

${ }^{1}$ Department of Psychiatry, Center for Cognitive Molecular Neuroscience,1st Medical Faculty of Charles University, Ke Karlovu 11, 12000 Praha 2, USA ${ }^{2}$ MitoGenetics LLC, 3 Bioscience Park Drive Suite 307, Farmingdale, NY, USA 11735

\begin{abstract}
The causes of pervasive developmental disorders have yet to be resolved. Needless to say, the etiology is complex as are the individual factors, especially in regard to autism. Certain findings may be integrated into early coherent models, but the heterogeneity of findings remains a central feature of autism. The present review examines contemporary areas of research and a few prominent theories specifically dealing with autism. The areas under scrutiny are divided into common academic compartments, such as biological, environmental. Autism represents a very timely topic due to its rising incidence in the population as well as changes in previous concepts occurring at this time. Besides the neurological, biological and epidemiological factors contributing and possibly initiating this disorder we discuss the possible involvement of endogenous morphine, especially in regard to depression and limbic functions. Lastly, we advance the theory that dysfunctional mitochondria appear to be involved in autism as well, explaining the widespread occurrence of its characteristics within the construct of susceptibility to stress and trauma. Thus, the diffuse manifestations of Pervasive Developmental Disorder occur potentially by altering energy processes.
\end{abstract}

Keywords: Autism; Pervasive developmental disorders; Causes

Abbreviations: PDD: Pervasive Developmental Disorders; ASD: Autism Spectrum Disorders; PDD NOS: Pervasive Disorder Not Otherwise Specified; CDD: Childhood Disintegrative Disorder; FRAXA: Fragile X Syndrome; MRI: Magnetic Resonance Imaging; SPECT: Single-Photon Emission Computed Tomography; EEG: Electroencephalography

\section{Introduction}

Pervasive developmental disorders (PDD), or autism spectrum disorders (ASD) currently have a high rate of occurrence worldwide, however, the causes of PDD are still under investigation. The umbrella term pervasive developmental disorder was first used in the 1980s, describing a class of disorders with the following characteristics: impairments in social interaction, imaginative activity, verbal and nonverbal communication skills and a limited number of interests and activities that tend to be repetitive [1]. Interestingly, these characteristics are found in respective normal behaviors of people, however, in autism they are exaggerated or diminished in their expression levels. This latter point has caused some investigators to regard autism as a mere manifestation in personality behavioral diversity, without using the term disorder [2]. However, it is our belief that this is a disorder since individuals afflicted with it can not-functional, lacking the ability to communicate and therefore, requiring medical and social services intervention. Pervasive developmental disorders are, according to the DSM-IV, categorized into 5 subtypes: autistic disorder, pervasive disorder not otherwise specified (PDD NOS, also called atypical autism), Rett's disorder, childhood disintegrative disorder (CDD) and Asperger's disorder. ICD-10 defines 8 subtypes of PDD: childhood autism; atypical autism; Rett's syndrome; other childhood disintegrative disorders; overactive disorder associated with mental retardation and stereotyped movements; Asperger syndrome; other pervasive developmental disorders and other pervasive disorders. DSM-V includes autism as it expresses itself in neurodevelopmental disorders and centralized autistic disorder, Asperger's disorder, and pervasive developmental disorder into autism spectrum disorder. The ratings of the symptoms of these disorders as a single continuum of mild to severe impairments in the two domains of social communication and restrictive repetitive behaviors/interests rather than being distinct disorders appears to be appropriate given their presence in normal time behaviors [3] Additionally, confounding accurate diagnosis to evaluate individuals who have marked deficits in social communication, but whose symptoms do not otherwise meet criteria for autism spectrum disorder" may be more appropriate in the social (pragmatic) communication disorder category. Current estimates of PDD prevalence are around 20 in 10,000 and the prevalence for PDD NOS is around 30 in 10,000 [4]. Thus, PDD (for various reasons and from a wide range of perspectives) has become one of the most frequent neurodevelopmental disorders in childhood. However, as indicated above, that data supports the hypothesis that this disorder is one of degree of negative behavioral expression of normal behaviors. Thus, given the central nervous systems (CNS) functional architecture, expression of the components of this affliction may be alone or in combination also being complicated by the degree of the various abnormalities "blend" into the final behavioral "output". Taking this into consideration, other research has aimed at a wide spectrum of specific areas and topics involving autism. Tsai asserts that based on behavioral and biological studies there is sufficient evidence to claim that PDD NOS are caused by a neurological abnormality but no specific causes were identified. According to Trottier the manifestation of autism is caused by a pathophysiologic process, arising from the interaction of an early environmental insult and a genetic predisposition, which was not defined [5]. Volkmar surmised that autism is thought to be one of the most heritable of all psychiatric conditions [6]. The issue today is simply what causes autism, if indeed it is one single event. In this regard, the current theory trend is a major step forward from the sensory and perceptual theories prevailing in the 1960s and 1970s, involving brain

*Corresponding author: Radek Ptacek, Department of Psychiatry, Center for Cognitive Molecular Neuroscience,1st Medical Faculty of Charles University, Ke Karlovu 11, 12000 Praha 2, USA, Tel: 00420739331970; E-mail: ptacek@neuro.cz

Received May 14, 2015; Accepted July 29, 2015; Published August 03, 2015

Citation: Ptacek R, Brejlova D, Ptackova H, Domkarova L, Raboch J, et al. (2015) Autism-A Multifaceted Diffuse Pathology. J Psychiatry 18: 315 doi: 10.4172/23785756.1000315

Copyright: (C) 2015 Ptacek R, et al. This is an open-access article distributed unde the terms of the Creative Commons Attribution License, which permits unrestricted use, distribution, and reproduction in any medium, provided the original author and source are credited 
Citation: Ptacek R, Brejlova D, Ptackova H, Domkarova L, Raboch J, et al. (2015) Autism-A Multifaceted Diffuse Pathology. J Psychiatry 18: 315 doi: 10.4172/2378-5756.1000315

Page 2 of 8

stem abnormalities [7]. A number of proposed current causes have been described, including medical conditions (e.g., phenylketonuria, fragile $\mathrm{X}$ syndrome, and tuberous sclerosis), perinatal impairment, and autoimmune disorders. Genetic origins are currently the focus of intensive research. Clarke postulates autism is one abnormality of behavioral expression, involving the normal spectrum of behaviors, which may be expressed abnormally [8]. The following discussion considers a modest speculation on the origin of autism (Table 1).
1. Genetic factors

2. Chromosomal abnormalities

3. Genetic susceptibility running in families

4. Non-genetic conditions

5. Dysfunctional Mitochondria

1. Brain dysfunctions

2. Altered pattern of evoked response potentials (Trottier et al. 1999)

3. Structural abnormalities in various regions of the brain

(Trottier et al. 1999)

4. Changes in temporal lobe

5. Cerebellum and limbic structures

6. Neocerebellum

7. Changes in limbic system (amygdala, hippocampus)

9. Neuroimaging

\section{A. Biological etiology}

fragile X syndrome (Gillberg and Coleman 1996; Fombonne 2003; Freitag 2007; Reddy 2005; Wassink et al. 2001; Bailey 1993a)

tuberous sclerosis (Gillberg and Coleman 1996; Fombonne 2003; Harrison and Bolton 1997; Gutierrez et al. 1998)

phenylketonuria (Gillberg and Coleman 1996)

chromosome 15 (Baker et al. 1994; Hotopf and Bolton 1995; Schroer et al. 1998; Cook 1998)

clusters of personality characteristics, language abnormalities, psychiatric disorders (Folstein and Piven 1991; Bolton et al. 1994)

infectious diseases (cytomegalovirus, congenital rubella, acute encephalopathy) (Lotspeich and Ciaranello 1993; Bailey et al. 1996)

(Stefano and Kream 2015a,b)

\section{B. Neurobiological factors}

reduced connectivity in the brain (Courchesne et al. 2001)

hypoactivation of a social processing brain network (Volkmar et al. 2004)
8. Neurological abnormalities

temporal lobe damage (Bachevalier 1994; Bachevalier 1996)

temporal lobe epilepsy (Piven et al. 1996)

temporal lobe enlargement (Piven et al. 1996)

alterations in neuronal size (Bauman et al. 1991; Raymond et al. 1996)

alterations in density (Bauman et al. 1991; Raymond et al. 1996)

alterations in dendritic branching (Bauman et al. 1991; Raymond et al. 1996)

reduction in granule and Purkinje cell density (Courchesne et al. 1994)

reduced density (Bauman 1996; Kemper and Bauman 1998)

reduced cell size (Bauman 1996; Kemper and Bauman 1998)

reduced dendritic arborization (Bauman 1996; Kemper and Bauman 1998)

abnormal electroencephalogram (Tanguay 2000)

PET: deficiencies in coordinated interaction between the cortical and subcortical systems (Courchesne 1991)

SPECT: hypoperfusion in the temporal region and the frontal lobe (Cederlund and Gillberg 2004)

MRI: megalencephaly in males (Piven et al. 1996)

\section{Neurochemical factors}

1. Dysfunction of cerebellar-cortical serotonergic pathways

(Chugani et al. 1997)

2. Overactive brain opioid systems (Trottier et al. 1999)

3. Changes in oxytocin neurotransmission (Trottier et al. 1999)

4. Dysfunction of cerebellar-cortical serotonergic pathways

(Chugani et al. 1997)

5. Hyperserotonemia (Cook et al. 1993)

Hospitalization during the neonatal period (Guillem et al. 2006

Matsuishi et al. 1999)

Insults early in gestation

Maternal ingestion of anticonvulsants (Moore et al. 2000)

Intrauterine effects

Pregnancy complications

Birth complications (Volkmar 2007; Piven et al. 1993)

Pre-, peri-, and postnatal complications

\section{Pre- and perinatal conditions}

thalidomide embryopathy (Trottier et al. 1999, Stromland et al. 1994)

high testosterone levels (Cohen-Bendahan et al. 2005)

high androgen levels (Voracek 2010; Powell et al. 2002; Goldberg and Lichten 1995; Baischer et al. 1995; Roos et al. 2011)

severe infections (Cederlund and Gillberg 2004)

second-trimester bleeding (Cederlund and Gillberg 2004)

pre-eclampsia (Cederlund and Gillberg 2004)

prolonged time of gestation (Deykin and MacMahon 1979; Knobloch and Pasamanick 1975;

Lobascher et al. 1970)

neonatal cyanosis (Deykin and MacMahon 1979; Knoblochand Pasamanick 1975; Lobascher et al. 1970) 
Citation: Ptacek R, Brejlova D, Ptackova H, Domkarova L, Raboch J, et al. (2015) Autism-A Multifaceted Diffuse Pathology. J Psychiatry 18: 315 doi: 10.4172/2378-5756.1000315

Page 3 of 8

umbilical strangulation (Deykin and MacMahon 1979; Knobloch and Pasamanick 1975; Lobascher et al. 1970)

severe neonatal icterus (Volkmar 2007)

Hyperbilirubinemia (Mazurek et al. 2013)

Intrauterine and neonatal factors

deviant intrauterine growth (Hultman et al. 2002; Bolton et al. 1997; Burd et al. 1999; Nelson 1991) fetal distress (Hultman et al. 2002; Bolton et al. 1997; Burd et al. 1999; Nelson 1991)

Antibodies against myelin basic protein (Trottier et al. 1999)

Elevated alpha interferon levels in the plasma (Stubbs 1995)

Migration (Gardener et al. 2009; Troisi et al. 2008; Haglund and

Kallen 2011; Dealberto 2011; Keen et al. 2010)

"Maternal unhappy emotional state" (Zhang et al. 2010)

High maternal adrenal androgen concentrations (James 2012)

Birth order

Antibody reactivity to certain foods (Lucarelli et al. 1995)

firstborns (Gardener et al. 2009; Troisi et al. 2008)

\section{E. Environmental factors}

Etiological and genetical heterogeneity (Volkmar 2007)

Theory of mind hypothesis (Baron-Cohen 1995)

Psychiatric disorders in relatives (major depression, social

phobia, affective disorders) (Tanguay 2000; Bolton et al. 1998;

Mazefsky et al. 2008)

Postnatal toxicities (Coleman 2003)

Table 1: Causes of PDD: a summary

\section{Biological Factors}

Until the 1960s, autism was assumed to be of psychogenic origin but the high incidence of mental deficiency as well as epileptic seizures led investigators to incorporate biological factors into its definition. A review by Rutter et al. concluded that most cases of autism are not secondary to or associated with specific medical disorders [9]. By contrast, Freitag has suggested that non-genetic medical conditions are minor risk factors for autism but they may be its most relevant cause [10]. In other words, they represent phenocopies of the disorder. At the time, this seemed very appealing, however, the depth of the associated diagnostic characteristics and their expression levels may warrant other considerations, e.g., cellular internal dynamics manifesting themselves abnormally regionally. One of the first postulates for considering genetic factors as a cause or contributing component of autism was the twin study by Folstein and Rutter, which described a highly increased concordance rate for autism in monozygotic twins (36\%) but not for dizygotic twins (0\%) [11]. In 1989, Steffenburg et al. found even higher concordance rates for monozygotic twins $(60 \%)$ in contrast to dizygotic twins (3\%) [12]. Twin studies on autism resulted in heritability estimates of $>90 \%$ for the phenotype of autism [10]. Interestingly, autism also can be associated with other medical disorders in $24.4 \%$ of the cases presented in those studies [13]. Genetic conditions such as fragile $\mathrm{X}$ syndrome, tuberous sclerosis, phenylketonuria can have a autistic comorbidity as with non-genetic conditions such as infectious diseases $[14,15]$. The frequency of these disorders in the population with autism is much greater than could be expected by chance, and importantly none are solely associated with autism. Thus, the heterogeneity of the autistic spectrum of disorders is widespread without an apparent connection. There are also a few findings about infectious diseases in relation to PDD, such as congenital rubella, acute encephalopathy, and cytomegalovirus [15]. Additionally, tuberous sclerosis and fragile $\mathrm{X}$ syndrome (FRAXA) are the most prevalent single-gene disorders in autism spectrum disorders. Gutierrez et al. described tuberous sclerosis in approximately in $40 \%$ of autistic persons, mostly in those with moderate to severe mental retardation and/or a seizure disorder [16]. Epidemiological studies $[17,18]$ demonstrate that the prevalence of tuberous sclerosis in children with autism is more than 100 times greater than expected. A number of authors $[19,20]$ have reported that about $2 \%-5 \%$ of autistic children and adolescents carry a full FRAXA mutation or FRAXA mosaics. According to other genetic studies, there is an association between autism markers and brain development, such as 3 markers of the c-Harvey-ros oncogene and the homeobox gene EN2. The most common chromosomal abnormalities include duplication of chromosomal material, especially chromosome 15 or the sex chromosomes. Reports of single-case chromosomal abnormalities are questionable, except for the numerous reports of deletions and duplications of chromosome 15, especially in the 15q11-13 region [21]. The $15 \mathrm{q}$ region from the maternally-derived chromosome is supposed to be the most commonly affected in autistic individuals $[22,23]$. The genetic epidemiology is complicated by variable expressivity and heterogeneity as noted earlier. Thus, it has been difficult to establish not only the origin of autism but also its mode of transmission. The data do not support a single gene model for autism, implying greater gene numbers are involved [24]. This can also be surmised because a significant number of parents of autistic children exhibit impaired executive functions, such as inadequate planning skills and lack of the flexibility of attention, increasing the target gene pool. Studies describe clusters of personality characteristics, language abnormalities, and psychiatric disorders in families with autism [25]. These clusters of symptoms also may serve as a manifestation of an underlying genetic susceptibility to autism and/or improper cellular communication processes in the brain.

\section{Pre- and perinatal Factors}

Studies of prenatal and perinatal complications did not show any constant association with autism [26], although in some cases positive associations were found. Guillem emphasizes the high number of perinatal complications and a high proportion of hospitalizations during the neonatal period in children with autism spectrum diseases [27]. In Japan, the prevalence of autistic disorders has been reported to be 3 times higher in children hospitalized in neonatal care units than in the general population [28]. In some cases, autism is associated with insults early in gestation, including thalidomide embryopathy in $4 \%$ to $5 \%$ of cases, probably due to damage to the CNS in the early stages 
of gestation [29]. Autism occasionally occurs as a result of maternal ingestion of anticonvulsants [30]. Certainly, these reported studies imply strongly a neurological component in autism origination that appears to transcend abnormalities in normal behavior expression by an individual. Intrauterine effects may result from genetic conditions of the mother, endangering the development of the fetus. According to consistent findings, the affected children as adults have a higher rate of pregnancy and birth complications than their siblings or controls [31] and several studies found significantly increased rates of obstetric complications in pregnancies [32-34]. The many similar and diverse abnormalities comprised in pre-, peri-, and postnatal complications: prolonged time of gestation, neonatal cyanosis, umbilical strangulation, and severe neonatal icterusall require a compelling theory for such a negatively dynamic disorder. Juul-Dam et al. found a significantly higher incidence of uterine bleeding in mothers of autistic children, and in the PDD NOS group a higher incidence of hyperbilirubinemia, but again no unifying feature could be established [35]. Cederlund and Gillberg recorded abundant pregnancy complications in $31 \%$ of the patients (including severe infections, second-trimester bleeding, and pre-eclampsia) as well as perinatal complications in $60 \%$ of the patients, but severe perinatal complications were rare [36]. The findings of a Swedish study suggested that the pathogenesis of autism may be based on intrauterine and neonatal factors related to deviant intrauterine growth or fetal distress [37]. These results support previous findings by other investigators $[38,39]$. Perinatal stress may cause significant brain damage and therefore probably be involved in initiating autism. It is noteworthy to mention that the research findings stress that birth complications are relatively non-specific and can be observed in both children with autism and healthy children, indicating the presence of other factors in this autistic emergence or that the abnormalities being examined may arise from other factors than autism. Volkmar argues that if birth complications are an etiologically relevant factor, autism would be expected to occur with increased frequency in populations with an increased risk for birth complications. An increased rate of birth complications is also found in children with cerebral palsy, severe mental retardation [40-42], chromosomal aberrations, and genetic disorders $[43,44]$. Thus, we propose that this interpretation is simplistic since comorbidities represent a fraction of any disorder, suggesting that shared commonalities exist and can be complicated in their pattern of expression. Voracek also has reported on the importance of exposure of the fetus to high androgen levels in the context of developing autism [45]. High androgen levels occur in women who are chronically stressed [46], chronically fatigued [47] chronically depressed [48] or exposed to fear-relevant stimuli during pregnancy [49]. Cohen-Bendahan et al. have hypothesized the key influence of high testosterone levels affecting the fetus arise from the fetus (not the mother) [50]. This hypothesis is the subject of ongoing work [51]. Antibodies against myelin basic protein are often found in children with autism. Those children also have increased eosinophil and basophil response to IgE-mediated reactions, suggesting neuro-immune involvement. In autistic children there are abnormally elevated alpha interferon levels in the plasma, which possibly influence cell growth, activation, and proliferation [52] further supporting a neuro-immune pro-inflammatory state existed [53].

\section{Neurobiological Factors}

The neurobiological involvement in autism encompasses data from the fields of neurophysiology, neurochemistry, neuroimaging and morphological research. A population-based study found $85 \%$ to $90 \%$ of autistic subjects show some indication of underlying brain dysfunction
[54]. The pattern of evoked response potentials and conduction time is altered in autistic children and structural abnormalities have been found in various regions of the brain. A number of autistic behaviors have been reported in individuals with temporal lobe damage [55,56] both temporal lobe epilepsy and temporal lobe enlargement are frequent [57]. Compounding these abnormal characteristics are those showing reduced connectivity in the autistic brain [58]. Volkmar proposed this condition is brought about by generalized hypoactivation of a social processing brain network, indicating a pervasive lack of social interest, engagement, motivation, or reactivity [59,60]. A number of authors, including $[61,62]$ emphasize the role of limbic system circuitry, particularly the amygdala and hippocampus, in causal models of autism. Postmortem studies repeatedly have described various abnormalities in these areas: such as; reduced density, cell size, and dendritic arborization in the amygdala, hippocampus, anterior cingulate, and mammillary bodies [63,64]. New to the consideration of autism etiology is the occurrence of endogenous morphine in these brain areas and its associated coupling to constitutive nitric oxide synthase stimulated nitric oxide release, which alters the physiological state of neurons and microglia [65,67]. Indeed, inappropriately stimulated macrophages and/or microglia can induced dysphoria [68,69] similar to psychiatric abnormalities noted in autism. Approximately $75 \%$ of autistic subjects show abnormalities on neurological examination [70]. About half of autistic patients have abnormal electroencephalogram results. Thus, autism may arise from abnormal CNS functioning. This hypothesis is based on the high incidence of epileptic seizures in autistic individuals. Tanguay reported that autistic persons show more EEG abnormalities than non-autistic controls, but the findings are varied and nonspecific as well as open to reinterpretation [71]. Singh et al. states that $58 \%$ of autistic individuals, compared with only $9 \%$ of controls, have antibodies reactive to myelin basic protein (anti-MBP) in their serum [72]. Minshew et al. suggested that the neural basis of autism is widespread cortical abnormalities sparing early sensory processes [73]. This hypothesis is based on models aimed at difficulties with complex information processing. A number of neurochemicals, including chemical messengers, have been investigated in respect to autism in the past several decades, but most abnormal findings have not been substantiated. Neurochemical studies have investigated the role of serotonin, epinephrine, and norepinephrine, since levels of these neurotransmitters are altered in autism [74]. Other hypotheses implicate overactive brain opioid systems and changes in oxytocin neurotransmission. Green et al. also have suggested that children with autistic disorder show alterations in the endocrine oxytocin system [75]. A frequently cited finding is the dysfunction of cerebellar-cortical serotonergic pathways [76]. Hyperserotonemia in autism is considered to be heterogenous, with some subjects having increased 5-HT uptake and another group having decreased 5- $\mathrm{HT}_{2}$ binding [77].

Studies of dopaminergic and catecholaminergic systems in autism have not yielded consistent results [78]. However, with dopamine serving as the major endogenous morphine precursor a new examination is in order. The evidence from neuroimaging studies indicates that dysfunctions in the cerebellum and possibly the temporal lobe and association cortex occur in autistic subjects. Recent studies found abnormalities in autism CNS at several levels, including the brain stem, cerebellum, limbic system, and association cortex [79]. Postmortem studies of autistic brains have not detected gross pathology, but recent studies have described alterations in neuronal size, density, and dendritic branching in the cerebellum and limbic structures [80] with the most consistent conclusion being the reduction in granule and Purkinje cell density in the neocerebellum [81]. Positron-emission 
tomographic studies have shown deficiencies in coordinated interaction between the cortical and subcortical systems that are involved in directed attention capabilities [82] with the consequence of impaired social communication skills. Cederlund and Gillberg reported that the most common SPECT finding was hypo-perfusion in the temporal region and the frontal lobe. A recent MRI study concluded that autistic subjects exhibit a specific sex-dependent pattern of cortical lobe enlargement-megalencephaly (an abnormally large brain)-accounting for increased brain size in autistic males.

With respect to macrocephaly (an abnormally large head, with megalencephaly being one of the potential causes) Lainhart et al. based on retrospective data, found that macrocephaly was not present at birth, but developed in early and middle childhood [83]. The cause of the increase in size has not yet been explained. Longitudinal MRI studies of the phenomena are needed. On the other hand, Deb and Thompson have stated that MRI studies have not confirmed brain abnormalities in autism and Tanguay suggests neural imaging results should be viewed with skepticism [84]. Then again, the absence of results using this technology may suggest the abnormal occurrences may be at the chemical communication level, including altering neuro-immune respective cellular behavior.

\section{Environmental Factors}

Gardener et al. has suggested that human migration is a risk factor for autism and this theory has been confirmed by others [85-88]. It has been theorized conditions in the countries of origin and the attempts to cope with Western society are stressful. We surmise this type of perceived stress creates a local neural environment manifesting itself as a proinflammatory state in susceptible individuals that if not alleviated becomes chronic potentially leading to autistic development depending on the functions affected. Indeed migration may just serve as a marker for this stressful event, in that other stressor may originate the process [89]. Dealberto also emphasizes the additional risk of autism to offspring of veiled women. Similarly, Zhang et al. have described a "maternal unhappy emotional state" as a risk factor for autism [90]. James has suggested that the association between maternal migration, the accompanying stress, and autism is mediated by high maternal adrenal androgen concentrations [91]. Furthermore, race is reported to be independently associated with a high risk for autism and pregnant black women have reportedly higher testosterone levels [92]. James has suggested that the higher risk for autism in the offspring of black women is the higher androgen level.

In yet another stressor, Gardener et al. has suggested that birth order is another risk factor for autism and that firstborns are at greater risk than children born later. The reason is supposed to be a stronger influence of maternal testosterone in the first trimester [93]. This can also be interpreted as stress being transmitted unintentionally to the baby by the mother reflecting nervousness concerning inexperience in mothering. Jaspers et al. identified early childhood aspects predictive of ASD: male gender, low level of education of the mother, low birth weight, social behavioral problems, language, psychomotor and eating problems in toddlers [94]. These results might serve as additional stress cues. Lucarelli et al. found that in autistic children, antibody reactivity to certain common foods is higher than in healthy subjects, again imposing stress on a susceptible individual [95]. Elimination of those foods from the diet substantially improved the behavioral symptoms. Mazurek et al. suggest that gastrointestinal problems are interrelated with and possibly have common underlying mechanisms with anxiety and sensory over-responsivity in ASD children [96]. Others have recently supported this hypothesis as well [97-99] In a mechanistic approach these recent works support the 1994 study by Stefano and colleagues, who suggested inappropriately activated immune cells could and do wander into the brain releasing common chemical messengers and that in so doing stimulates abnormal behavioral outcomes, e.g., autism-like.

In order to be thorough it should be mentioned that the mumpsmeasles-rubella vaccine had been considered as a possible cause of autistic disorders but epidemiological and case-control studies deny any increased risk caused by vaccination [100-102]. Therefore, this kind of vaccination cannot be considered as a risk factor for the development of autism. Season of birth has been linked to autism as well, citing factors such as the effects of weather, differences in nutrition, and season-specific medical problems during pregnancy [103]. On the contrary, Tanguay stated that no consistent seasonal trends emerged; children with autistic-like conditions were most often born in May and November but seasonal influences on the development of autism are weak and not consistent. In all probability seasonality does impose stress, again autism may emerge in individuals prone to developing this disorder because, in part, they are stress susceptible, as noted earlier. Higher maternal age used to be considered as a possible risk factor but recent studies have not found consistent evidence of this [104]. Coleman stated that the possibility of postnatal toxicities has been added to the list of environmental concerns in autism [105]. Clarke opens up very interesting discussion about the real influence of mercury pollution that may be directly connected to IQ increase/ decrease but also autism symptoms.In our interpretation this again represents a stressor impacting a susceptible individual, targeting areas associated with autism behavioral characteristics.

\section{Co-morbidity Indicative Factors}

Volkmar described heterogeneity both etiological and genetic (the etiological heterogeneity being the involvement of both genetic and environmental etiologies, and the genetic heterogeneity being the involvement of either several different mutations at a single genetic locus or by several genes at different loci).There is considerable evidence that autism is both etiologically and genetically heterogeneous. In the 1990s, Clarke and Baron-Cohen introduced the "theory of mind". Here, the social dysfunction in autism is the result of impaired processes specifically in conceiving of other people's and one's own mind. Thus, it may be looked at as a personality disorder not a full blown neurological abnormality.

A number of scientists, such as Bolton et al. , report a higher incidence of major depression and social phobia in first-degree relatives of autistic persons; $64 \%$ percent of the depressed parents had their first episode prior to the birth of the autistic child [106]. Mazefsky et al. refers to broader autism phenotype in family members of individuals with ASD as well as high rates of affective psychiatric disorders [107]. We also speculated that limbic involvement is present, in that presentation of the abnormal behaviors occurs within a dopamine defined disorder, e. g., depression, where endogenous morphine is involved [108-113] Over expression of the dopaminergic driven behaviors may be do, as noted in these cited reports, to a morphine insufficiency condition, which may be a contributing factor in autism.

\section{Conclusion}

Autism currently represents one of the most discussed diagnostic categories in the area of psychopathology. Multifactorial etiology opens the door to new questions not answers. It is one of biggest "biomedical 
problems" in psychiatry. Causal contributions to the manifestation of pervasive developmental disorders may be classified into six categories: biological etiology, neurobiological factors, neurochemical factors, pre- and perinatal conditions, environmental and comorbidity factors. Accordingly, the underlying etiological mechanisms responsible for the manifestation of complex autistic behaviors are by nature multifactorial and include disproportionately unknown unregulated genetic, developmental, and environmental components [114,115]. Preferential evidence favoring genetically driven etiological factors is compelling, is inherently complex, but perhaps underestimates the contribution of environmental determinants [116,117]. Along these lines of evidence, neuroimaging studies have indicated the involvement of broad and developmentally interrelated neural systems, contradicting the notion of single core deficits. We surmise this indeed is the case. We further presume that the future aim of research defining and specifying causes of pervasive developmental disorders is to gradually narrow the scope of research to those key areas of discovery based on prevailing concepts and their commonalities. However, given the complexity of autism, we may indeed be faced with anabnormality that manifests itself from varying altered structures and brain areas. The tendency to "lump" all into a single event may be fatally flawed for autism [118-128].

Recently, another theory has emerged, which is quite compelling in its ability to explain the multitude of widespread characteristics that exist in defining autism as well as other psychiatric disorders. This involves the mitochondrion an important eukaryotic cellular organelle involved with generating ATP, powering the cells many reactions, normally without abrupt interruptions. It is surmised that mitochondrial dysfunction when it occurs targets the CNS because of its level of oxygen utilization. In so doing stress, trauma, any negative stimulus or stimuli would damage neurons initiating neural and neuro-immune disorders, e.g., autism. Indeed if genetic susceptibilities are present the target becomes more specific as opposed to a more diffuse manifestation of abnormality. Given the universal presence of mitochondria in CNS cells this theory provides for a credible explanation for the complications and characteristics that emerge in autism.

\section{Acknowledgements}

GBS was partially funded by Mitogenetics, LLC (Sioux Falls, South Dakota). A conflict of interest is not present regarding the documents content.

\section{References}

1. Tsai LY (1998) Pervasive Developmental Disorders. National Information Center for Children and Youth with Disabilities. FS20.

2. Clarke RP (1993) A theory of general impairment of gene-expression manifesting as autism. Personality and individual differences 14: 465-482.

3. American Psychiatric Association (2013) Diagnostic and statistical manual of mental disorders: DSM-5. Washington: American Psychiatric Publishing 947.

4. Fombonne E (2009) Epidemiology of Pervasive Developmental Disorders. Pediatr Res 65: 591-8.

5. Trottier G, Srivastava L, Walker CD (1999) Etiology of infantile autism: a review of recent advances in genetic and neurobiological research. J Psychiatry Neurosci 24: 103-115.

6. Volkmar FR (2007) Autism and Pervasive Developmental Disorders. Cambridge University Press 356.

7. Ornitz EM (1985) Neurophysiology of infantile autism. J Am Acad Child Psychiatry 24: 251-262.

8. Clarke RP (2015) Rising-falling mercury pollution causing the rising-falling IQ of the Lynn-Flynn effect, as predicted by the antiinnatia theory of autism and IQ. Personality and Individual Differences 82: 46-51.

9. Rutter M, Bailey A, Bolton P, Le Couteur A (1994) Autism and known medical conditions: myth and substance. J Child Psychol Psychiatry. Feb 35: 311-22.
10. Freitag CM (2007) The genetics of autistic disorders and its clinical relevance: a review of the literature. Mol Psychiatry 12: 2-22.

11. Folstein S, Rutter M (1977) Infantile autism: a genetic study of 21 twin pairs. J Child Psychol Psychiatry 18: 297-321.

12. Steffenburg S, Gillberg C, Hellgren L, Andersson L, Gillberg IC, et al. (1989) A twin study of autism in Denmark, Finland, Iceland, Norway and Sweden. J Child Psychol Psychiatry 30: 405-16.

13. Gillberg C, Coleman M (1996) Autism and mental disorders a review of the literature. Dev Med Child Neurol 38: 191-202.

14. Bailey LJ, Ciaranello RD (1993) The neurobiology and genetics of infantile autism (review). Int Rev Neurobiol 35: 87-129.

15. Bailey A, Phillips W, Rutter M (1996) Autism: towards an integration of clinical genetic, neuropsychological, and neurobiological perspectives. J Child Psychol Psychiatry 37: 89-126.

16. Gutierrez GC, Smalley SL, Tanguay PE (1998) Autism in tuberous sclerosis complex. J Autism Dev Disord 28: 97-103.

17. Fombonne E (2003) Epidemiological surveys of autism and other pervasive developmental disorders: an update. J Autism Dev Disord 33: 365-82.

18. Harrison JE, Bolton PF (1997) Annotation: tuberous sclerosis. J Child Psychol Psychiatry 38: 603-14.

19. Reddy KS (2005) Cytogenetic abnormalities and fragile-X syndrome in autism spectrum disorder. BMC Med Genet 6: 3-19.

20. Wassink TH, Piven J, Patil SR (2001) Chromosomal abnormalities in a clinic sample of individuals with autistic disorder. Psychiatr Genet 11: 57-63.

21. Cook EH Jr (1998) Genetics of autism. Mental Retardation and Developmenta Disabilities 4: 113-120.

22. Hotopf M, Bolton P (1995) A case of autism associated with partial tetrasomy 15. J Autism Dev Disord 25: 41-9.

23. Schroer RJ, Phelan MC, Michaelis RC, Crawford EC, Skinner SA, et al. (1998) Autism and maternally derived aberrations of chromosome $15 \mathrm{q}$. Am J Med Genet 76: 327-36.

24. Jorde LB, Hasstedt SJ, Ritvo ER, Mason-Brothers A, Freeman BJ, et al. (1991) Complex segregation analysis of autism. Am J Hum Genet 49: 932-8.

25. Folstein SE, Piven J (1991) Etiology of autism: genetic influences. Pediatrics 87: 767-73.

26. Bauman ML, Courchesne E, Denckla MB, Folstein SE, James LS, et al. (1991) An update on autism: a developmental disorder- introduction. Pediatrics 87: v-vi.

27. Guillem P, Cans C, Guinchat V, Ratel M, Jouk PS (2006) Trends, perinata characteristics, and medical conditions in pervasive developmental disorder. Dev Med Child Neurol. 48: 896-900.

28. Matsuishi T, Yamashita Y, Ohtani Y, Ornitz E, Kuriva N, et al. (1999) Brie report: incidence of and risk factors for autistic disorder in neonatal intensive care unit survivors. J Autism Dev Disord 29: 161-6.

29. Stromland K, Nordin V, Miller M, Akerstrom B, Gillberg C (1994) Autism in thalidomide embryopathy: a population study. Dev Med Child Neurol 36: 351-6.

30. Moore SJ, Turnpenny P, Quinn A, Glover S, Lloyd DJ, et al.( 2000) A clinical study of 57 children with fetal anticonvulsant syndromes. J Med Genet 37: 489-97.

31. Piven J, Simon J, Chase GA, Wzorek M, Landa R, et al. (1993) The etiology of autism: pre-, peri- and neonatal factors. J Am Acad Child Adolesc Psychiatry 32: $1256-63$

32. Deykin EY, MacMahon B (1979) The incidence of seizures among children with autistic symptoms. Am J Psychiatry 136: 1310-2.

33. Knobloch H, Pasamanick B (1975) Some etiologic and prognostic factors in early infantile autism and psychosis. Pediatrics 55: 182-91.

34.Lobascher ME, Kingerlee PE, Gubbay SS (1970) Childhood autism: an investigation of aetiological factors in twenty-five cases. $\mathrm{Br} \mathrm{J}$ Psychiatry 117 $525-9$

35. Juul-Dam N, Townsend J, Courchesne E (2001) Prenatal, perinatal, and neonatal factors in autism, pervasive developmental disorder-not otherwise specified, and the general population. Pediatrics 107: E63.

36. Cederlund M, Gillberg C (2004) One hundred males with Asperger syndrome: 
a clinical study of background and associated factors. Dev Med Child Neurol 46: 652-60.

37. Hultman CM, Sparén $P$, Cnattingius S (2002) Perinatal risk factors for infantile autism. Epidemiology 13: 417-23.

38. Burd L, Severud R, Kerbeshian J, Klug MG (1999) Prenatal and perinatal risk factors for autism. J Perinat Med 27: 441-50.

39. Nelson KB (1991) Prenatal and perinatal factors in the etiology of autism. Pediatrics 87: 761-6.

40. Miller G (1989) Minor congenital anomalies and ataxic cerebral palsy. Arch Dis Child 64: 557-62.

41. Nelson KB, Ellenberg JH (1986) Antecedents of cerebral palsy: multivariate analysis of risk. N Engl J Med 315: 81-6.

42. Rantakallio $P$, von Wendt $L$ (1985) Risk factors for mental retardation. Arch Dis Child 60: 946-52

43. Bailey A, Bolton P, Butler L, Le Couteur A, Murphy M, et al. (1993) Prevalence of the fragile $X$ anomaly amongst autistic twins and singletons. J Child Psychol Psychiatry 34: 673-88.

44. Bailey A, Luthert P, Burd P, Le Couteur A, Rutter M, et al. (1993) Autism and megalencephaly. Lancet 341: 1225-6.

45. Voracek M (2010) Fetal androgens and autism. Br J Psychiatry 196: 416-7.

46. Powell LH, Lovallo WR, Matthews KA, Meyer P, Midgley AR, et al. (2002) Physiologic markers of chronic stress in premenopausal middle-aged women. Psychosom Med 64: 502-9.

47. Goldberg M, Lichten J (1995) High androgen levels in chronic fatigue patients. $\mathrm{J}$ Clin Endocrinol Metab 80: 3390-1.

48. Baischer W, Koinig G, Hartmann B, Huber J, Langer G (1995) Hypothalamicpituitary-gonadal axis in depressed pre-menopausal women: elevated blood testosterone concentrations compared to normal controls. Psychoneuroendocrinology 20: 553-9.

49. Roos A, Robertson F, Lochner C, Vythilingum B, Stein DJ (2011) Altered prefrontal cortical function during processing of fear relevant stimuli in pregnancy. Behav Brain Res 222: 200-5.

50. Cohen-Bendahan CC, van Goozen SH, Buitelaar JK, Cohen-Kettenis PT (2005) Maternal serum steroid levels are unrelated to fetal sex: a study in twin pregnancies. Twin Res Hum Genet 8: 173-7.

51. Auyeung B, Baron-Cohen S, Ashwin E, Knickmeyer R, Taylor K, et al. (2009) Fetal testosterone and autistic traits. Br J Psychol 100: 1-22.

52. Stubbs G (1995) Interferonemia and autism. J Autism Dev Disord 25: 71-3.

53. Esch T, Stefano GB (2002) Proinflammation: A common denominator or initiator of different pathophysiological disease processes. Medical Science Monitor 8: 1-9.

54. Steffenburg S (1991) Neuropsychiatric assessment of children with autism: population-based study. Dev Med Child Neurol 33: 495-511.

55. Bachevalier J (1994) Medial temporal lobe structures and autism: a review of clinical and experimental findings. Neuropsychologia 32: 627-48.

56. Bachevalier J (1996) Brief report: medial temporal lobe and autism: a putative animal model in primates. J Autism Dev Disord 26: 217-21.

57. Piven J, Arndt S, Bailey J, Andreasen N (1996) Regional brain enlargement in autism- a magnetic resonance imaging study. J Am Acad Child Adolesc Psychiatry 35: 530-6.

58. Courchesne E, Karns CM, Davis HR, Ziccardi R, Carper RA, et al. (2001) Unusual brain growth patterns in early life in patients with autistic disorder. An MRI study. Neurology 57: 245-54.

59. Baron-Cohen S (1995) Mind blindness: An Essay on Autism and Theory of Mind. Cambridge MA: MIT Press 200.

60. Schultz RT, Grelotti DJ, Klin A, Kleinman J, Van der Gaag C, et al. (2003) The role of the fusiform face area in social cognition: Implications for the pathobiology of autism. Philos Trans R Soc Lond B Biol Sci 358: 415-27.

61. Baron-Cohen S, Ring HA, Bullmore ET, Wheelwright S, Ashwin C, et al. (2000) The amygdala theory of autism. Neurosci Biobehav Rev 24: 355-64.

62. Saitoh O, Karns CM, Courchesne E (2001) Development of the hippocampal formation from 2 to 42 years: MRI evidence of smaller area dentata in autism. Brain 124: 1317-24.

63. Bauman ML (1996) Brief report: Neuroanatomic observations of the brain in pervasive developmental disorders. J Autism Dev Disord 26: 199-203.

64. Kemper TL, Bauman M (1998) Neuropathology of infantile autism. J Neuropathol Exp Neurol 57: 645-52

65. Zhu W, Ma Y, Cadet P, Yu D, Bilfinger TV, et al. (2003) Presence of reticuline in rat brain: A pathway for morphine biosynthesis. Mol.Brain Res 117: 83-90.

66. Zhu W, Ma Y, Bell A, Esch t, Guarna M, et al. (2004) Presence of morphine in rat amygdala: Evidence for the mu3 opiate receptor subtype via nitric oxide release in limbic structures. Med.Sci.Monit 12: BR433-BR439.

67. Stefano GB, Kim E, Liu Y, Zhu W, Casares F, et al. (2004) Nitric oxide modulates microglial activation. Med Sci Monit 10: BR17-BR22.

68. Stefano GB, Bilfinger TV, Fricchione GL (1994) The immune neuro-link and the macrophage: Postcardiotomy delirium, HIV-associated dementia and psychiatry. Prog Neurobiol 42: 475-488.

69. Fricchione GL, Mendoza A, Stefano GB (1994) Morphine and its psychiatric implications. Adv Neuroimmunol 4: 117-132.

70. Lisch S, Rühl D, Sacher A, Schmötzer G, Poustka A, et al. (1993) Beziehungen zwischen autistischem Syndrom und dem FraX-Syndrom. In: Baumann P editor. Biologische Psychiatrie der Gegenwart. Vienna: Springer Verlag 390-8.

71. Tanguay PE (2000) Pervasive Developmental Disorders: A 10-Year Review. J Am Acad Child Adolesc Psychiatry 39: 1079-95.

72. Singh VK, Warren RP, Odell JD, Warren WL, Cole P (1993) Antibodies to myelin basic protein in children with autistic behavior. Brain Behav Immun 7 : 97-103.

73. Minshew NJ, Sweeney JA, Bauman ML (1997) Neurological aspects of autism. In: Cohen DJ, Volkmar FR. editors. Handbook of autism and pervasive developmental disorders. New York: Wiley 344-369.

74. Minderaa RB, Anderson GM, Volkmar FR, Akkerhuis GW, Cohen DJ, et al. (1999) Noradrenergic and adrenergic functioning in autism. Biological psychiatry $36: 237-241$

75. Green L, Fein D, Modahl C, Feinstein C, Waterhouse L, et al. (2001) Oxytocin and Autistic Disorder: Alterations in Peptide Forms. Biol Psychiatry 50: 609-13.

76. Chugani DC, Muzik O, Rothermel R, Behen M, Chakraborty P, et al. (1997) Altered serotonin synthesis in the dentatothalamocortical pathway in autistic boys. Ann Neurol 42: 666-9.

77. Cook EH, Jr. Arora RC, Anderson GM, Berry-Kravis EM, Yan SY, et al. (1993) Platelet serotonin studies in hyperserotonemic relatives of children with autistic disorder. Life Sci 52: 2005-15.

78. Volkmar FR, Lord C, Bailey A, Schultz RT, Klin A (2004) Autism and pervasive developmental disorders. J Child Psychol Psychiatry 45: 135-70.

79. Petit E, Hérault J, Martineau J, Perrot A, Barthélémy C, et al. (1995) Association study with two markers of a human homeogene in autism. J Med Genet 32 269-74.

80. Raymond GV, Bauman ML, Kemper TL (1996) Hippocampus in autism-a Golg analysis. Acta Neuropathol 91: 117-9.

81. Courchesne E, Townsend J, Saitoh O (1994) The brain in infantile autism: posterior fossa structures are abnormal. Neurology 44: 214-23.

82. Courchesne E (1991) Neuroanatomic imaging in autism. Pediatrics 87: 781-90.

83. Lainhart JE, Piven J, Wzorek M, Landa R, Santangelo SL, et al. (1997) Macrocephaly in children and adults with autism. J Am Acad Child Adolesc Psychiatry 36: 282-90.

84. Deb S, Thompson B (1998) Neuroimaging in autism. Br J Psychiatry 173: 299-302.

85. Gardener H, Spiegelman D, Buka SL (2009) Prenatal risk factors for autism: comprehensive meta-analysis. Br J Psychiatry 195: 7-14

86. Haglund NG, Kallen KB (2011) Risk factors for autism and Asperger syndrome Perinatal factors and migration. Autism 15: 163-83.

87. Dealberto MJ (2011) Prevalence of autism according to maternal immigran status and ethnic origin. Acta Psychiatr Scand 123: 339-48. 
Citation: Ptacek R, Brejlova D, Ptackova H, Domkarova L, Raboch J, et al. (2015) Autism-A Multifaceted Diffuse Pathology. J Psychiatry 18: 315 doi: 10.4172/2378-5756.1000315

Page 8 of 8

88. Keen DV, Reid FD, Arnone D (2010) Autism, ethnicity and maternal immigration. Br J Psychiatry196: 274-81.

89. Stefano GB, Benson H, Fricchione GL, Esch T (2005) The Stress Response: Always good and when it is bad. New York: Medical Science International.

90. Zhang X, Lv CC, Tian J, Miao RJ, Xi W, et al. (2010) Prenatal and perinatal risk factors for autism in China. J Autism Dev Disord 40: 1311-21.

91. James WH (2012) A potential explanation of some established major risk factors for autism. Dev Med Child Neurol 54: 301-5.

92. Henderson BE, Bernstein L, Ross RK, Depue RH, Judd HL (1988) The early in utero oestrogen and testosterone environment of blacks and whites: potential effects on male offspring. Br J Cancer 57: 216-8.

93. Troisi R, Hoover RN, Thadhani R, Hsieh CC, Sluss P, et al. (2008) Maternal, prenatal and perinatal characteristics and first trimester maternal serum hormone concentrations. $\mathrm{Br} \mathrm{J}$ Cancer 99: 1161-4.

94. Jaspers M, de Winter EF, Buitelaar JK, Verhulst FC, Reijneveld SA, et al. (2013) Early Childhood Assessments of Community Pediatric Professionals Predict Autism Spectrum and Attention Deficit Hyperactivity Problems. J Abnorm Child Psychol 41: 71-80.

95. Lucarelli S, Frediani T, Zingoni AM, Ferruzzi F, Giardini O, et al. (1995) Food allergy and infantile autism. Panminerva Med 37: 137-41.

96. Mazurek MO, Vasa RA, Kalb LG, Kanne SM, Rosenberg D, et al. (2013) Anxiety, Sensory Over-Responsivity, and Gastrointestinal Problems in Children with Autism Spectrum Disorders. J Abnorm Child Psychol 41: 165-76.

97. Frye RE, Slattery J, MacFabe DF, Allen-Vercoe E, Parker W, et al. (2015) Approaches to studying and manipulating the enteric microbiome to improve autism symptoms. Microb Ecol Health Dis 26: 26878.

98. Dinan TG, Stilling RM, Stanton C, Cryan JF (2015) Collective unconscious: How gut microbes shape human behavior. J Psychiatr Res 63: 1-9.

99. Toh MC, Allen-Vercoe E (2015) The human gut microbiota with reference to autism spectrum disorder: considering the whole as more than a sum of its parts. Microb Ecol Health Dis 26: 26309.

100. Chen W, Landau S, Sham P, Fombonne E (2004) No evidence for links between autism, MMR and measles virus. Psychol Med 34: 543-53.

101. Smeeth L, Cook C, Fombonne E, Heavey L, Rodrigues LC, et al. (2004) MMR vaccination and pervasive developmental disorders: a case-control study. Lancet 364: 963-969.

102. Taylor B, Miller E, Farrington CP, Petropoulos MC, Favot-Mayaud I, et al. (1999) Autism and measles, mumps, and rubella vaccine: no epidemiological evidence for a causal association. Lancet 353: 2026-9.

103. Bolton P, Pickles A, Harrington R, Macdonald H, Rutter M (1992) Season of birth issues, approaches and findings for autism. J Child Psychol Psychiatry 33: 509-31.

104.Mouridsen SE, Rich B, Isager T (1993) Brief report: parental age in infantile autism, autistic-like conditions, and borderline childhood psychosis. J Autism Dev Disord 23: 387-96.

105. Coleman M (2003) Autism: known and unknown. Dev Med Child Neurol 95 31-4.

106. Bolton PF, Pickles A, Murphy M, Rutter M (1998) Autism, affective and other psychiatric disorders: patterns of familial aggregation. Psychol Med 28: 385-95.

107. Mazefsky CA, Williams DL, Minshew NJ (2008) Variability in Adaptive Behavior in Autism: Evidence for the Importance of Family History. J Abnorm Child Psychol 36: 591-9.

108.Kream RM, Stefano GB, Ptacek R (2010) Psychiatric Implications of Endogenous Morphine: Up-To-Date Review. Folia Biologica: Journal of Cellular and Molecular Biology 56: 231-241.

109. Ptacek R, Kuzelova H, Stefano GB (2011) Dopamine D4 Receptor Gene DRD4 and its association with Psychiatric Disorders. Medical Science Monitor 17: RA215-RA220.
110. Stefano GB, Ptacek R, Kuzelova H, Kream RM (2012) Endogenous morphine: Up-to-date review 2011. Folia Biologica: Journal of Cellular and Molecular Biology 58: 49-56.

111. Kream RM, Kuzelova H, Kralickova M, Ptacek R, Stefano GB (2012) Comorbidity and self medication in schizophrenia: Involvement of endogenous morphine signaling mechanisms. Current Drug Targets 13: 1454-1457.

112. Stefano GB, Kream RM, Mantione KJ, Ptacek R (2013) Endogenous morphine, stress and psychiatric disorders- review of actual findings.

113. Ptacek R, Kuzelova H, Stefano GB, Raboch J, Kream RM, et al. (2014) ADHD and growth: questions still unanswered. Neuroendocrinology Letters 35: 1-6.

114. Grafodatskaya D, Chung B, Szatmari P, Weksberg R (2010) Autism spectrum disorders and epigenetics. J Am Acad Child Adolesc Psychiatry 49: 794-809.

115. Levy SE, Mandell DS, Schultz RT (2009) Autism. Lancet 374: 1627-38.

116. Bailey A, Le Couteur A, Gottesman I, Burd P, Simonoff E, et al. (1995) Autism as a strongly genetic disorder: evidence from a British twin study. Psychol Med 25: 63-77.

117. Chamak B (2010) Autism: overestimation of the genetic origins. Med Sci 26 659-662.

118. Bailey AJ (1993) The biology of autism. Psychol Med 23: 7-11.

119. Baker P, Piven J, Schwartz S, Patil S (1994) Brief report: duplication of chromosome 15 qll-13 in two individuals with autism. J Autism Dev Disord 24: 529-35.

120. Bolton P, Macdonald H, Pickles A, Rios P, Goode S, et al. (1994) A casecontrol family history study of autism. J Child Psychol Psychiatry 35: 877-900.

121. Bolton PF, Murphy M, Macdonald H, Whitlock B, Pickles A, et al. (1997) Obstetric complications in autism: consequences or causes of the condition? J Am Acad Child Adolesc Psychiatry 36: 272-81.

122. Honda H, Shimizu Y, Rutter M (2005) No effect of MMR withdrawal on the incidence of autism: a total population study. J Child Psychol Psychiatry 46: $572-9$.

123. Kream RM, Stefano GB (2009) Endogenous morphine and nitric oxide coupled regulation of mitochondrial processes. Med Sci.Monit 15: RA263-RA268.

124.Kuželová H, Ptáček R, Macek M Jr (2010) The serotonin transporter gene (5HTT) variant and psychiatric disorders. Neuroendocrinology Letters 31: 4-10.

125. Ptáček R, Kuželová H, Stefano G (2011) Genetics in Psychiatry Up-to-date Review. Neuroendocrinology Letters 32: 389-399.

126. Stefano GB, Kim C, Mantione KJ, Casares FM, Kream RM (2012) Targeting mitochondrial biogenesis for promoting health. Med Sci Monit18: SC1-SC3.

127. Stefano GB, Kream RM (2015) Nitric Oxide Regulation of Mitochondrial Processes: Commonality in Medical Disorders. Annals of Transplantation in press.

128. Stefano GB, Kream RM (2015) Psychiatric Disorders Involving Mitochondria Processes. Psychology Observer 1: 1-6. 